\title{
As mulheres dos estatutos no Congresso Nacional Brasileiro
}

\author{
Bruna Potechi' (iD 0000-0003-4162-2757 \\ 'Universidade Federal de São Carlos, Programa de Pós-Graduação em Antropologia \\ Social, São Carlos, SP, Brasil. 13565-905 - ppgas.coord@ufscar.br
}

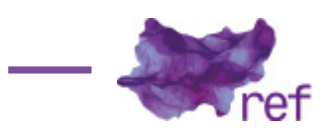

Resumo:Este artigo analisa as transformações da categoria jurídica mulher a partir da apresentação de um projeto de lei (PL) em 2003 propondo um Estatuto da Mulher (PL 1399 de 2003). A análise apresentada contrasta os documentos apresentados no legislativo sobre o projeto de lei, assim como as falas proferidas em Comissão Especial criada para elaborar parecer ao Projeto de Lei do Estatuto da Mulher. O objetivo é demonstrar como os discursos em comissão faziam referência à mulher de uma forma materna e natural. Estas condições associadas à mulher retrocederiam os avanços jurídicos da categoria na busca pela igualdade. Assim, observamos com outro Estatuto da Mulher, apresentado em 1937, como discursos proferidos em 2004 na Câmara dos Deputados ainda mantêm mulher em uma condição de sujeito controlado pela família, anulando os avanços jurídicos observados.

Palavras-chave: mulher; direitos; lei; antropologia

The Women of the Statutes in Brazilian National Congress

Abstract:This article analyzes the transformation of woman as a legal category, by looking at debates on the running of a bill that proposed a Woman's Statute in Brazil's legislative chambers in 2003-2004. It contrasts documents presented at the legislative chambers with speeches made at the Special Committee created to report the bill. This comparison shed light on the manner in which speeches made at the Committee cast woman as an inherently maternal subject embedded in specific family relations. Such an association of woman retrocedes legal improvements obtained in the pursuit of gender equality. Additionally, comparing the discourses of 2004 to another bill that proposed a Woman's Statute in 1937 illuminates how woman remains a subject subordinated to the notion of family, which contradicts the legal improvements for woman's equality gained in the last decades.

Keywords: woman; rights; law; anthropology

\section{Introdução}

Após a promulgação do Estatuto da Criança e do Adolescente em 1990 e a apresentação e aprovação do Estatuto do ldoso em 2003 são apresentados diversos projetos de lei propondo estatutos no Congresso Nacional. Entre 2000 e 2003 são apresentados o Estatuto do Portador de Necessidades Especiais (posteriormente apresentado como Estatuto da Pessoa com Deficiência), o Estatuto da Igualdade Racial, o Estatuto do Desporto, o Estatuto da Terra e o Estatuto da Mulher. Este último é apresentado enquanto projeto de lei e tramita por dois anos na Câmara dos Deputados em Comissão Especial sendo posteriormente arquivado. Ainda que a Constituição de 1988 tenha ampliado direitos e reconhecido "grupos sociais merecedores de especial tutela" (Maristela Nascimento INDALENCIO, 2007, p. 37), os avanços em relação aos direitos fundamentais com a Constituição deixaram ainda em aberto posterior necessidade de ampliação de direitos e de regulamentação de direitos já estabelecidos para garantia de sua real efetividade (INDALENCIO, 2007, p. 43). Referente aos direitos relativos a mulheres, a promulgação da Constituição atual foi considerada um grande avanço para a categoria, algumas o definindo como fim da busca da igualdade jurídica. No entanto, vemos, com o Estatuto da Mulher, que a definição de mulher no teor da proposição soa dúbio, ou que esta definição poderia questionar a referida igualdade conquistada em 1988. 
A própria formulação de novas leis complementares em formato de estatutos pode apresentar paradoxos, visando à proteção de determinada categoria e produzindo automaticamente exclusão de outras (Claudia FONSECA; Andrea CARDARELLO, 1999). Fonseca afirma que quando uma categoria é defendida, defendem-se seus direitos; "assim, se existem pessoas mais merecedoras de direitos, devem existir pessoas menos merecedoras" (FONSECA; CARDARELLO, 1999, p. 31). Com o Estatuto da Criança e do Adolescente, "evidentemente, esses jovens eram contemplados pelo ECA ma non troppo. Bastava a administração isolá-los dos 'mais humanos' (com menos de 18 anos) para poder agir em liberdade, sem medo de censura" (FONSECA; CARDARELLO, 1999, p. 17). O movimento da autora mostra como a construção de categorias produz dois movimentos, um de inclusão e proteção e outro de exclusão de direitos e consequentemente de diminuição dos mesmos. No caso do Estatuto da Mulher, os debates apresentados em diferentes tipos de documentos no Congresso Nacional parecem paradoxais. Por um lado, eles tentavam definir as mulheres a serem incluídas no estatuto e, por outro, definiam mulher por um viés retrógrado e contrário ao movimento de conquista da igualdade jurídica com a Constituição atual.

O projeto de lei (PL) 1399 de 2003 dispondo sobre um "Estatuto da Mulher" foi apresentado em julho na Câmara dos Deputados. Ao analisar a tramitação do Projeto de Lei e dos documentos que foram apresentados junto a ele, percebemos que parte dos debates contrastava qual deveria ser a mulher atingida pelo Estatuto. Em seu artigo $2^{\circ}$, o projeto de lei prescrevia:

Considera-se para os efeitos desta Lei, às mulheres: chefe de família, mãe solteira, cabeça-decasal, soro positivo, portadoras de necessidades especiais, ex-presidiária e àquelas que comprovarem incapacidade de manter seu próprio sustento, quer seja, por estar desempregada ou por motivo de doenças (BRASIL, 2003).

As emendas apresentadas ao Projeto de Lei debatem - em sua maioria - qual a mulher a ser contemplada pelo Projeto de Lei. A maioria das propostas visa a alterar o Projeto de Lei considerando mulher como uma categoria universal, sem nenhuma exclusão; no entanto, outros recortes da categoria mulher são propostos, como o de direcionar o estatuto para mulheres que não estejam contempladas em outras leis e estatutos, como mulheres idosas e mulheres, crianças e adolescentes. Parte dos debates realizados em Comissão Especial criada para proferir parecer ao projeto de lei do Estatuto da Mulher, com atividades em 2004, destacava a igualdade jurídica já conquistada pela mulher com a Constituição promulgada em 1988. Esta implicava, conforme observamos nas falas, igualdade jurídica não apenas entre mulheres, mas também entre mulheres e homens. Por outro lado, parte dos discursos proferidos em Comissão Especial se referia à causa "mulher" associando-a a papéis familiares, retrocedendo nos avanços e emancipação jurídica que a categoria jurídica teria alcançado (Florisa VERUCCI, 1994; Roberto Maurício GENOFRE, 1995), processo este de conquista de direitos anterior à promulgação da Constituição atual.

Os dados apresentados neste artigo e suas consequentes reflexões são resultado de pesquisa de doutorado que analisa a produção de leis no legislativo brasileiro a partir de algumas proposições sobre mulher na Câmara dos Deputados. Esta análise toma a produção legislativa como um campo em constante fabricação de documentos, sendo grande parte destes acessível ao público. Assim, a pesquisa se desenvolveu a partir de uma etnografia de documentos, artefatos culturais que, segundo Annelise RILES (2006), ganham atenção na Antropologia com o advento da modernidade. Ainda conforme a autora, seriam tanto documentos pessoais, quanto bilhetes de transporte, cupons fiscais, entre outros. Na pesquisa, documentos são tanto projetos de lei, emendas, votos, pareceres, como aqueles que contêm os registros das reuniões, como notas taquigráficas, arquivos de áudio e vídeo, pauta, ata, resoluções. Esta distinção entre os dois grupos é fundamental, visto que o primeiro grupo, que passamos a chamar de 'documentos escritos', tem produzido algumas considerações sobre a categoria a ser analisada, enquanto o segundo grupo de documentos, ou os 'registros', parece fazer diferentes conexões do termo. Ainda que sejam tipos de documentos distintos, entendo que ambos se enquadram na maneira como a disciplina tem olhado para esta produção de artefatos. Das três formas de análise de documentos na disciplina descrita por Matthew S. HULL (2012), uma pela forma, uma afetiva e uma que conectasse forma e conteúdo, nos aproximamos mais da última, descrevendo como formas acabam por alterar o conteúdo dos documentos analisados. ' Observamos, assim, através de documentos, a fabricação de uma proposta legislativa que fabrica uma concepção jurídica de "mulher".

A análise a partir do projeto de lei do Estatuto da Mulher apresentado em 2003 observa formas como mulher, como categoria jurídica, é concebida em diferentes documentos e momentos. Para tal, este artigo esboça primeiramente como mulher enquanto categoria jurídica foi se modificando para atingir seu status de igualdade com a Constituição atual. Nesse processo de transformações da mulher como categoria e dos direitos a ela atribuídos estão as mulheres

\footnotetext{
' Sobre essa abordagem, ver FELDMAN, llana. Governing Gaza: Bureaucracy, Authority, and the Work of Rule, 1917-
} 1967. Durham: Duke University Press, 2008. 
organizadas ou não enquanto movimentos sociais sujeitos protagonistas dessa história. Numa segunda etapa, apresento como a categoria mulher aparecia em outro período com a apresentação do projeto de lei do Estatuto da Mulher em 1937. Em seguida, passo a explorar os 'documentos escritos', aqueles que, apresentados com o Projeto de Lei, descrevem a categoria jurídica mulher. Eles ficavam em geral acessíveis pela página de tramitação da proposição nos sites das referidas Casas, Câmara ou Senado. A terceira parte do artigo apresenta como os discursos proferidos na Comissão Especial do Estatuto da Mulher em 2004 consultados nos registros das reuniões concebiam o que poderia ser entendido por mulher. Se vínhamos discutindo como mulher era concebida como categoria jurídica em leis, vemos que os discursos mudam seu argumento, passando a defini-las de outra forma, e como outra categoria. Comparar as conexões da categoria mulher no Estatuto da Mulher de 1937 nos permite observar como parte dos discursos proferidos em 2004 retrocedia os avanços jurídicos prescritos em leis.

\section{Igualdade}

Todos são iguais perante a lei, sem distinção de qualquer natureza, garantindo-se aos brasileiros e aos estrangeiros residentes no País a inviolabilidade do direito à vida, à liberdade, à igualdade, à segurança e à propriedade, nos termos seguintes: I - homens e mulheres são iguais em direitos e obrigações, nos termos desta Constituição; [...] (BRASIL, 1988).

Na Constituição Federal Brasileira atual, datada de 1988, a categoria mulher é acrescida de direitos estabelecidos em leis anteriores. A incorporação de determinados direitos a mulheres igualando-as a homens demonstra um avanço não apenas em direitos, mas também naquilo que é concebido como mulher em leis, ou seja, nessa enquanto categoria jurídica. No Brasil, o reconhecimento e a garantia dos direitos das mulheres eram impasses nas antigas constituições. O reconhecimento da igualdade entre os sexos só se dá pela primeira vez na Constituição de 1934. Constituição que teve a primeira mulher eleita e foi a primeira a reconhecer o direito das mulheres votarem (Branca Moreira ALVES, 1980). Entretanto, esta mesma Carta Constitucional manteve mulher em condições de desigualdade jurídica, como ressalvas em relação ao voto e mantendo - Código Civil que atribuía direitos específicos à mulher quando casada. Já as Constituições posteriores - de 1937 e 1946 - suprimem a referência à igualdade entre os sexos reduzindo o corpo do texto e retrocedendo em relação à igualdade jurídica que fora atribuída na Carta de 1934. Na Constituição de 1967 a distinção de sexo, assim como de raça, trabalho, religião e convicções políticas é incluída no corpo do texto. Mesmo que a igualdade, sem a menção de sexo, conste nas constituições brasileiras, não poderíamos pressupor que isto implique igualdade entre homem e mulher - mesmo considerando aqui apenas em termos legais. Podemos entender que a igualdade era referente apenas a homens - ou apenas àqueles considerados cidadãos (Salete Maria da SILVA, 2008). Em relação ao voto, por exemplo, antes de 1934 não existia na Constituição um impedimento de voto às mulheres, mas estas não votavam, pois não eram consideradas incorporadas às leis, ou na categoria cidadão.

Parte da bibliografia descreve esse processo de ampliação de direitos para a categoria mulher na Constituição atual como uma conquista do movimento de mulheres iniciado no fim do período ditatorial, movimento que ganha força no Brasil a partir da década de 70 (Lianda Lima CARVALHO, 2012; Cynthia SARTI, 1988). O movimento feminista, que já tinha espaço em outros países da Europa ou mesmo nos Estados Unidos, começa a se intensificar e propor formas de organização no país. Isto num momento de ditadura militar, o que acaba colocando tais organizações dentro da busca pela volta da democracia. Nesse momento as feministas que se organizavam politicamente estavam ligadas a partidos de esquerda, sofrendo um impulso em 1975, com o Ano Internacional da Mulher decretado pela ONU, o que facilitou a organização e a criação de grupos feministas e de mulheres de reflexão em um período ditatorial. Movimentos de mulheres ligadas a causas populares, inclusive com a igreja católica, também atuavam junto às mulheres e às organizações tidas ou não como feministas (SARTI, 1988). A partir de 1978 esses movimentos começam a atuar politicamente com a emergência política do país, levando demandas para eleições e candidatos a parlamentares. No começo da década de 80 elas realizam congressos e constroem espaços de garantia e pressão de direitos dentro e frente ao Estado, como o Centro de Defesa dos Direitos da Mulher (iniciativa pioneira) em Belo Horizonte (SARTI, 1988; Ana Alice Alcântara COSTA, 2013).

Em 1985 no contexto do grande movimento de massas Diretas Já e da transição democrática em curso no país, discute-se, no âmbito do movimento de mulheres, sobre a pertinência da criação de um órgão no governo federal que desenvolvesse políticas públicas para melhorar a condição da mulher, propondo novas leis, novos programas, aconselhando a presidência e aos ministérios e desenvolvendo projetos específicos, contando para tal com dotação orçamentária e recursos humanos (Jaqueline PITANGUY, 1988, p. 1). 
Em 1985 é criado o Conselho Nacional dos Direitos da Mulher (CNDM), "vinculado ao Ministério da Justiça, para promover políticas que visassem eliminar a discriminação contra a mulher e assegurar sua participação nas atividades políticas, econômicas e culturais do país" (http://www.spm.gov.br/assuntos/conselho). Já em 1985, o CDNM inicia duas campanhas: Constituinte pra valer tem que ter Palavra de Mulher e Constituinte pra Valer tem que ter Direitos de Mulher. A primeira campanha é voltada para a eleição de mulheres para a Constituinte; a segunda para a formulação da Constituição.

Em 1986 o CNDM reúne centenas de mulheres para a elaboração de uma carta com propostas para os constituintes (PITANGUY, 1988, p. 2). A "Carta das Mulheres Brasileiras aos Constituintes" tem como preocupação a efetividade e garantia do princípio de igualdade, sendo contrária às práticas de discriminação (pauta mais ampla que sexo) e propondo inclusive a criminalização de "afronta ao princípio de igualdade". Contém também reivindicações específicas sobre família, trabalho, saúde, educação e cultura, violência e questões nacionais e internacionais. A carta foi entregue em 1987, na inauguração do Congresso Constituinte, a Ulisses Guimarães, Presidente do Congresso Nacional. Segundo Jaqueline Pitanguy (1988), é neste momento que se inicia o movimento de luta das mulheres que ficou conhecido como Lobby do Batom. Este designaria a união das deputadas e para fora do Congresso, união entre movimentos de mulheres (e, em alguns casos, feministas) e as deputadas através do Conselho Nacional dos Direitos da Mulher. Durante a Constituinte, essa organização contava com 26 deputadas - de um total de 559 deputados eleitos.

Nesse processo, as mulheres descritas como sujeitos históricos são deputadas, militantes, cientistas sociais e advogadas. Elas mesmas acabam por se tornar as principais referências aqui citadas para demonstrar o percurso de conquistas históricas do movimento de mulheres e as transformações jurídicas com o processo da Constituinte. Parte das advogadas e cientistas sociais também descreve outros processos que culminaram na ampliação de direitos das mulheres, ou que permitiram a transformação da categoria mulher nas leis brasileiras.

A conquista do voto feminino se deu em medida pela pressão exercida pelas feministas e sufragistas da época. No começo do século XX, algumas mulheres da elite burguesa criam a Federação Brasileira pelo Progresso Feminino (FBPF), dirigida e comandada por Bertha Lutz (Branca ALVES, 1980; Teresa Cristina de Novaes MARQUES, 2016). Esta mesma que assumirá posteriormente como deputada em 1936, sendo a segunda mulher a ocupar o cargo. Em 1932 elas conseguem o decreto presidencial que dava direito de voto às mulheres e a incorporação de tal direito na Constituição de 1934. Em 1962 ocorre outro fato importante para o reconhecimento de direitos das mulheres, com a aprovação de uma lei para a modificação do Código Civil. Até então, a mulher, quando casada, não tinha autonomia para trabalhar sem a permissão do marido, não herdava bens do casal, e as decisões do casal eram de autoridade do marido. A Lei em questão era o Estatuto da Mulher Casada, de autoria de Romy Medeiros e Orminda Bastos (Florisa VERUCCI, 1999). O projeto é aprovado enquanto Estatuto Civil da Mulher e incorporado ao Código Civil, e ainda que tenha revogado a incapacidade da mulher casada, manteve a chefia masculina da sociedade conjugal, a possibilidade de deserdar filhas "desonestas" e o defloramento da mulher ignorado pelo marido como motivo para anulação de casamento (VERUCCI, 1999, p. 79).

É apenas com a Constituição de 1988 que a igualdade jurídica entre homens e mulheres é alcançada, ainda que o processo de transformação da categoria mulher tenha sido processo de mais longa data. Essas transformações da categoria mulher em leis se deram em processos em que mulheres se organizam - seja ou não em movimentos sociais. Na Constituinte de 88 , com a abertura democrática do país, foi possível que este processo culminasse em uma Carta que ficou conhecida como Constituição Cidadã, que além de ter a noção de cidadania como pano de fundo, ampliou direitos de outras categorias, como índio, negro, crianças, pessoas com deficiência, idosos e presidiários (SILVA, 2008). Processo que, segundo Silva (2008), foi também alcançado via mobilização e pressão exercida pelas mulheres na busca pela democracia e ampliação de direitos. Nesse meio vimos como mulheres, enquanto sujeitos organizados, propiciaram que mulher, como termo jurídico, se transformasse no modelo atual que teria como inerente o princípio da igualdade. É nesse contexto, com essa concepção jurídica de mulher, que é apresentado em 2003, na Câmara dos Deputados, o Projeto de Lei do Estatuto da Mulher.

\section{Outro Estatuto, outra mulher}

Em 1937 foi apresentado o Projeto de Lei 736 (BRASIL, 1937) sobre um Estatuto da Mulher em um cenário totalmente diferente do Estatuto da Mulher apresentado em 2003. ${ }^{2}$ Era a primeira legislatura com a presença feminina após a primeira Constituição a dar direito de voto às mulheres. A autoria e iniciativa do projeto de lei são atribuídas à Bertha Lutz que, embora não eleita, toma

\footnotetext{
${ }^{2}$ Agradeço a Coordenação de Relacionamento, Pesquisa e Informação da Câmara dos Deputados e ao Museu
} Bertha Lutz da Universidade de Brasília pelo material fornecido. 
posse como deputada federal em julho de 1936, após falecimento do deputado Cândido Pessoa, de quem era suplente (Lia Gomes Pinto de SOUSA; Mariana Moraes de Oliveira SOMBRIO; Maria Margaret LOPES, 2005). Ela se tornou a segunda mulher a ocupar cargo de deputada na Câmara dos Deputados e, juntamente com a primeira deputada eleita no Brasil, Carlota Pereira de Queiróz, estabeleceu uma Comissão Especial na Câmara dos Deputados para redigir um Estatuto da Mulher, "com o fim expresso de regulamentar os dispositivos da legislação ordinária de acordo com os direitos e obrigações constitucionais da cidadã" (Marilene SOW, 2010). Ambas as deputadas defendiam questões de cunho feminista para a época, como licença-maternidade, igualdade de salários (Ricardo ORIÁ, 2009). Enquanto Bertha Lutz era uma das principais referências das feministas da época no Brasil, Carlota Pereira de Queiroz era médica e tinha sido eleita por São Paulo com expressividade em votos após a Revolução Constitucionalista (MARQUES, 2016). Lutz teria participado da Comissão preparatória do Anteprojeto da Constituição reunida em 1932 (SOUSA; SOMBRIO; LOPES, 2005), e Queiroz participado diretamente como primeira deputada eleita para uma Constituinte. As demandas na Constituinte para e pelas mulheres eram desde igualdade salarial a denúncias de nacionalidade e estado civil, licença maternidade remunerada e acesso a cargos públicos. O voto feminino, tendo sido incorporado naquela Constituição, fora a principal bandeira da Federação Brasileira pelo Progresso Feminino (FBPF) fundada e dirigida por Lutz.

A FBPF era reconhecia pela luta pelos direitos das mulheres no país, luta esta impulsionada com o sufrágio e posteriormente incentivando candidaturas de parlamentares. No entanto, ainda que se declarassem feministas, elas mantinham discursos mantendo alianças com a lgreja Católica, que no mesmo momento garante o direito de voto de religiosos e de ter candidatos, portanto, a FBPF não rompia com a manutenção do lar e da família que seria considerada como inata à mulher (MARQUES, 2016). Estes discursos conseguiam apoio inclusive de Getúlio Vargas, ainda que esta posição, muitas vezes considerada conservadora, como em relação a não se posicionar sobre o divórcio, tenha gerado inúmeras críticas de jornais na época (MARQUES, 2016). Isto, por um lado, mantinha associações políticas da FBPF e da própria Lutz; por outro, desavenças entre ela e a deputada Carlota Pereira de Queiroz refletiram nas conquistas de ambas para as mulheres no curto período enquanto parlamentares (ORIÁ, 2009; MARQUES, 2016). Este curto período se deu devido ao fechamento do Congresso Nacional em novembro de 1937 por Getúlio Vargas com o início do Estado Novo.

O projeto de lei 736 de 1937 é apresentado em Comissão Especial do Estatuto da Mulher em outubro de 1937. A Comissão, no entanto, existia desde setembro de 1936, por iniciativa de Lutz, e começa a discutir propriamente suas matérias em janeiro de 1937 (MARQUES, 2016). Dois foram os projetos apresentados à Comissão por Lutz: um primeiro em abril de 1937 e um segundo apenas em outubro daquele ano (MARQUES, 2016). Em abril fora apresentado o anteprojeto do Departamento Nacional da Mulher, e em outubro o Estatuto da Mulher. O projeto de lei do Estatuto da Mulher (PL 736/1937) contém 150 artigos, que "(...) constituem um importante diagnóstico das condições sociais que afligiam as mulheres" (MARQUES, 2016, p. 127). Na "exposição de motivos", texto que antecede o projeto de lei, são enfatizados os direitos atribuídos à mulher na Constituição de 1934. Na exposição de motivos do projeto de Lei do Estatuto da Mulher o sufrágio universal é então utilizado como um pontapé inicial do que deveria ser a conquista de direitos para as mulheres. A argumentação do Projeto de Lei é que enquanto a Constituição Federal de 1934 tinha dado à mulher igual condição que ao homem, legislações anteriores, e ainda em vigor, não eram assim - como o Código Penal, o Código Civil e o Código Comercial.

O Código Civil em vigor datava de 1916 e considerava a mulher, principalmente a casada, incapaz. O Código Comercial em vigor datava do Império e em 1937 já tinha 87 anos, segundo consta na exposição de motivos do Projeto de Lei. Ele impedia a mulher de ser corretora ou leiloeira. Já o Código Penal em vigor datava de 1890, e segundo Miriam Steffen VIEIRA (2011), crimes de estupro e defloramento estavam relacionados à honra da família, onde a moral da vítima era crucial para, num processo judicial, serem deliberados crime e sentença. Na exposição de motivos do projeto de lei do Estatuto da Mulher de 1937 o Código Penal de 1890 é colocado como injusto à mulher, pois todas as penas e crimes teriam mesmo peso para homem e mulher, com exceção de crime de adultério, infanticídio e para fazer sua defesa de violações sexuais.

No texto de 1937 existe um apelo pela busca da igualdade, para que a igualdade de votar e ser votada seja transposta para outras leis, que colocavam essa mesma igualdade em risco. O Estatuto reescreve alguns direitos que já estariam na Constituição de forma a não permitir outras interpretações a partir de outras leis. Trata, portanto, de nacionalidade, direitos políticos, de trabalho civil, comercial; inclui a mulher em condição de igual ao homem e dá-lhe tal condição independente do estado civil - aqui, claramente um diálogo com o Código Civil. No Art. $7^{\circ}$ do Estatuto está presente uma distinção biológica que fere os princípios de igualdade para o modelo atual da Constituição: "A mulher habilitada é assegurada preferência na orientação, direcção, execução, applicação fiscalisação dos serviços no julgamento de medidas, e, na solução dos problemas decorrentes das condições biológicas especiaes da mulher". Essas ressalvas à diferença 
entre os sexos são recorrentes no Projeto de Lei - condições e características de instintos maternos também presentes em discursos de Lutz durante sua carreira política (MARQUES, 2016, p. 130). Além disso, mais que reconhecer as diferenças biológicas, o projeto de lei discorre e dá pena - que claramente já eram dadas - a casos de aborto e infanticídio. A defesa da preparação domésticovocacional ainda está presente e é institucionalizada pela proposta de lei. O Título III "Estatuto Cultural", Capítulo I, é nomeado "Do preparo da mulher para a vida, o lar e o trabalho". Neste, em seu Art. 17, parágrafo $1^{\circ}$, "parallelamente com a instrucção geral receberá ella reparo domesticosocial que a habilite as funcções de dona de casa e mãe". A manutenção do valor da família e do papel na sociedade é altamente visível no projeto de lei de 1937, ainda que ele pareça tentar incorporar todas as mulheres. Embora se declarassem feministas, neste momento, as mulheres atuam como aliadas dessa manutenção da moral, dos costumes, da família.

Pensemos bem. São verdadeiramente necessárias taes restricções á capacidade da mulher? A opinião feminina organizada, que sempre se manteve dentro dos preceitos sãos e moraes da família, que não é extremista, mas procede com moderação e cautela, não os julga assim. Aponta-as com erro de interpretação de phenomenos psychologicos (BRASIL, 1937, p. 2).

O projeto de lei que fora apresentado em 01 de outubro de 1937 deixa de tramitar com o fechamento do Congresso Nacional em novembro de 1937, com o Estado Novo, e segundo Oriá (2009), as divergências entre Carlota e Bertha, como sobre a proposta de Bertha pela criação de um Departamento Nacional da Mulher ao qual Carlota é contrária, dificultaram o avanço do Projeto do Estatuto da Mulher. Ainda que mantenha um discurso sobre a defesa da igualdade para as mulheres, o Projeto do Estatuto da Mulher de 1937 nos mostra diferenças significativas na construção da igualdade almejada e consequentemente na definição da mulher como sujeito titular de direitos. Diferenças biológicas, de educação, formação, punição e morais são mantidas no conteúdo do projeto desenhando um cenário em que pouco ainda se questionava desses lugares ocupados pela mulher.

\section{Um Estatuto da Mulher}

O projeto de lei do Estatuto da Mulher é apresentado pelo deputado Renato Cozzolino (PSC-RJ) acompanhado de justificativa. Ainda que o projeto de lei não tenha sido transformado em lei, ele tramita por dois anos na Câmara dos Deputados. Durante sua tramitação são produzidos diversos documentos e registros sobre a importância ou necessidade de um Estatuto da Mulher, sobre qual a mulher a ser atingida pelo Estatuto e sobre mulheres na vida dos parlamentares. Ao ser apresentada na Casa, a matéria foi lida em Plenário, e foi então à MESA (Mesa diretora da Câmara) que constituiu Comissão Especial destinada a proferir parecer sobre o PL 1399 de 2003. ${ }^{3}$ No ano seguinte ocorreram as reuniões da Comissão Especial, que foram acompanhadas por notas taquigráficas. Em 11 de novembro de 2004 ocorre a última atividade da Comissão registrada no acompanhamento da matéria na página de tramitação da Câmara. A matéria foi arquivada.

É possível acompanhar a tramitação de um projeto de lei pelo site da Câmara dos Deputados ou Senado Federal. Cada Casa mantém em seu site a tramitação interna de cada proposição legislativa, com indicações de datas de apresentação, origem, encaminhamentos e para onde cada proposta segue. Nesta página de tramitação estão indicadas as datas e locais de apresentações de demais 'documentos escritos' como atos da presidência, requerimentos, emendas, votos, pareceres. Eles costumam ser assinados por pelo menos um parlamentar. Através da análise da página de tramitação da Câmara do PL 1399/2003 e dos 'documentos escritos' que ali se encontram vimos que a tramitação do PL e o possível motivo de sua aprovação seriam pelo Projeto de Lei propor preencher uma lacuna referente a discriminações e diferenças relativas a todas as mulheres - como diferenças sociais, políticas e econômicas.

O presente Projeto de Lei, que dispõe sobre o Estatuto da Mulher, tem por objetivo básico assegurar à mulher brasileira o direito de exercer sua cidadania e viver a vida com maior dignidade. Convoca a sociedade a refletir sobre as dificuldades que as mulheres enfrentam para se firmar nos campos social, políico e econômico. Em todo o mundo, em pleno século XXI, a mulher é submetida a violências de todos os tipos: discriminações, espancamentos, violência sexual, abusos e crueldades, inclusive a doméstica. Esses fatores têm tirado da mulher o direito de exercer plenamente seus direitos dentro da sociedade onde vive. Dessa forma, destina-se este Projeto a atender milhões de brasileiras, garantindo seus direitos quer seja no âmbito da Saúde, Habitação, da Educação, da Previdência, da Assistência Social, Jurídica, e outros (BRASIL, 2003, p. 10).

As emendas apresentadas ao Projeto de Lei, todas sendo 'emendas substitutivas', propunham alterar as mulheres alcançadas pela proposta inicial do Projeto de Lei, como vimos em seu artigo

\footnotetext{
${ }^{3}$ Comissões Especiais podem ser criadas quando o assunto demande três ou mais comissões. No caso, seriam as comissões de Trabalho, de Administração e Serviço Público, Educação e Cultura, Seguridade Social e Família, Finanças e Tributação e Constituição e Justiça e de Redação.
} 
$2^{\circ}$. A maioria prescrevia a inclusão de todas as mulheres, pois, segundo justificativas apresentadas nos parágrafos das emendas, o contrário feriria o princípio de isonomia da Constituição Federal onde todos são iguais. Aparecem diferentes possibilidades de mulheres alcançadas pelo Estatuto, ou então, diferentes possibilidades de compreender aquilo que é chamado de mulher no Projeto de Lei 1399/2003. Uma emenda, da deputada Ann Pontes (PMDB-PA), sugere a alteração para o alcance do Estatuto para a universalidade de mulheres, mas fazendo ressalva: sugerindo prioridade para as mais vulneráveis, que seriam as listadas pelo projeto de lei original. É dada proteção a algumas mulheres que não estariam contempladas em leis anteriores.

O Projeto, tal como apresentado, é completamente inadequado quanto à técnica legislativa, utilizando linguagem que mais se assemelha a uma peça de ação afirmativa do que à lei. A presente emenda pretende que a definição contida no Art. $2^{\circ}$ estabeleça claramente a universalidade dos direitos do Estatuto a todas as mulheres e, especialmente, às elencadas no Art. $2^{\circ}$ do texto originário (ex-presidiárias, chefes de família, mães solteiras etc.) que são designadas de forma mais abrangente, como determina a boa técnica legislativa (BRASIL, 2004, p. 1).

A deputada Telma de Souza (PT-SP) apresenta 21 emendas ao projeto de lei, sendo que a princípio parece defender a isonomia da Constituição Federal. Na EMC 4, ela dá nova redação ao art. 2०: "A mulher goza de todos os direitos fundamentais inerentes à pessoa humana, sem prejuízo da proteção integral (...)" (BRASIL, 2004a, p. 1). Na emenda é proposto que a defesa do estatuto seja universalizante sem determinar condicionalidades da mulher alcançável pelo Estatuto. Ao mesmo tempo, remete à condição (talvez ainda mais universal) dos direitos da mulher enquanto pessoa humana. Na EMC 8 a mesma deputada propõe a criação de Centros de Acolhimento destinados ao amparo e à assistência da mulher em situação de risco pessoal e social (BRASIL, 2004b). Já na EMC 21 é colocada uma condicionalidade às mulheres idosas, já que estas estariam contempladas no Estatuto do Idoso.

Inclua-se o seguinte § Único ao Art. 15: A partir de 60 anos, para garantir o disposto no Caput do Artigo, os casos serão regidos pelo Estatuto do Idoso. Justificativa: O Estatuto do Idoso contempla, de forma integral, as necessidades da mulher idosa (BRASIL, 2004c, p. 1).

Em outra emenda a deputada Yeda Crusius (PSDB-RS) sugere que o Estatuto seja da mulher hipossuficiente - emenda que deixa mais claro que estas mulheres não estariam dentro de uma categoria mulher mais abrangente, e, portanto, deveriam ser incluídas na categoria a partir da iniciativa do estatuto. As diferentes propostas das mulheres alcançadas no Estatuto da Mulher nos sugerem que o que pode ser entendido por mulher, naquela proposição específica, implica uma multiplicidade de definições. Nesse caso, e tanto nas leis em geral, mulher não deve ser apreendido como um conceito pronto, definido, contemplando todas as pessoas do sexo/gênero feminino. Entretanto, ainda que os 'documentos escritos', como projeto de lei e sua justificativa, e as emendas apresentadas subsequentemente demonstrem discussões acerca da definição de mulher na proposição legislativa, os registros das reuniões da Comissão Especial do Estatuto da Mulher tomam outro caminho, e neste caminho, mulher acaba sendo definida como um sujeito a partir de condições específicas.

\section{As mulheres nos discursos}

Durante o ano de 2004 são realizadas as reuniões da Comissão Especial do Estatuto da Mulher, totalizando 9 (nove) reuniões. ${ }^{4}$ Tivemos acesso aos registros das reuniões através de notas taquigráficas que, diferente de trazerem 'documentos escritos', contêm 'registros' dos discursos de parlamentares e depoentes nas reuniões da Comissão. Enquanto os 'documentos escritos' estavam falando de mulher num sentido de definir qual seria a mulher atingida pela proposta de lei, e como fazer recortes respeitando a isonomia da Constituição Federal, os 'discursos' pareciam atribuir outra forma à mulher. A justificativa da apresentação do projeto de lei pelo deputado Renato Cozzolino não é a mesma nos 'documentos escritos' e no seu 'discurso' na Comissão Especial do Estatuto da Mulher. Na justificativa que acompanha o projeto de lei como 'documento escrito' é ressaltada a necessidade de proteção da mulher devido às injustiças e desigualdades sociais vivenciadas. Já quando o autor do projeto de lei se pronuncia sobre as razões de apresentação do projeto de lei em Comissão Especial ele apresenta uma justificativa de proteção se referindo a um sonho que teve, onde mulheres se tornariam um bem valioso e necessário para a reprodução da espécie. Esta fala é proferida no início da primeira reunião da Comissão Especial em 2004.

Sra. Presidenta, demais membros da Comissão, amigas e amigos, há algumas semanas tive um sonho que foi um pesadelo e um pesadelo que foi um sonho: uma epidemia assolava o mundo e apenas atingia as mulheres, que faleciam. Em dado momento, a imprensa divulgava que todas as mulheres haviam sucumbido. Passaram-se dias, meses, e, de repente, descobriram que existia

\footnotetext{
${ }^{4}$ As reuniões da Comissão Especial se realizaram nas datas: 10/03/2004, 17/03/2004, 14/04/2004, 28/04/2004, 05/
} 05/2004, 12/05/2004, 18/05/2004, 15/06/2004 e 11/11/2004. 
uma única sobrevivente, que tinha no sangue alguma substância que the conferira condições de vencer aquela epidemia - e ela morava no Brasil. Mais do que depressa, o Presidente mandou as Forças Armadas buscarem essa mulher para protegê-la. Mais de 10 mil homens foram buscá-la. Colocaram-na na Casa da Moeda, pois era o tesouro maior do Brasil e do mundo. Colocaram em prontidão o Comandante das Forças Armadas. Lá estavam todos tomando conta daquele tesouro. O Presidente tomou um susto enorme. Jovens se suicidavam por terem perdido as noivas; homens de idade média e mais velhos enfartavam por terem perdido as suas mulheres. O mundo começou a se desequilibrar, a se perder. Nesse sonho, havia uma fila de cerca de 10 mil homens querendo se casar com aquela mulher, que se chamava Eva. O Presidente da República enviava uma MP à Câmara dizendo que ele seria o noivo, para continuidade da espécie. A oposição derrubou a MP. Os ministros queriam ser os noivos e manter a espécie. Os Estados Unidos propuseram a troca do nosso tesouro pelo pagamento da dívida externa. Por um instante, o Ministro da Fazenda resolveu que isso seria interessante, mas uma revolução interna foi instalada no Brasil e o Ministro caiu. Os mais ricos homens queriam se casar com Eva, guardada na Casa da Moeda não apenas pelo Exército, Marinha e Aeronáutica, mas também pelas Polícias Federal, Civil e os Bombeiros. Sim, meus amigos, já não se viam mais no nosso litoral aquelas curvas, aquela alegria, a mãe, a mulher, a filha. Elas não mais existiam. Apenas existia Eva. A verdade é que, em determinado momento, ao observarem a guarda, descobriram que todos os seguranças de Eva haviam sido assassinados e que ela tinha fugido com um capitão do Corpo de Bombeiros para um recanto no Centro-Oeste do nosso País. Escutei um ruído longe, distante, um barulho aqui, acolá, e acordei. Então, pude fazer uma reflexão profunda: é a mulher que nos dá a vida, é a mulher que torna doce a nossa vida. Por isso, meus amigos, a vida é justamente isso. Minha família é composta de 5 pessoas: minha mãe, Juraci; meu pai, José; meu irmão mais velho, José, o Rafael e eu. 0 meu irmão mais novo era deficiente mental; viveu conosco até os 24 anos de idade. Muitos diziam "que cruz que carrega aquela família", mas minha mãe nos dava equilíbrio. Meu pai trabalhava muito, mas era a minha mãe quem trazia a estrutura e o equilíbrio para a família. Meu irmão, que para muitos era uma cruz, para minha mãe era a alegria. Ela transformava tudo em alegria. $\mathrm{Na}$ manhã seguinte ao sonho, ao chegar ao meu gabinete, pedi que fizessem um levantamento de todas as leis específicas para a mulher. Deparei-me com alguns projetos de lei e me perguntei por que não propor a criação do Estatuto da Mulher. Assim nasceu, de um pesadelo, um sonho que V. Exas. terão condições de transformar em realidade. Muito obrigado (BRASIL, 2004).

Diferente da justificativa apresentada com o projeto de lei, em seu 'discurso', mulher deixa de ser pautada como forma de suprir discriminações e é exposta como um bem que precisa de proteção. Esta ótica de proteção, de bem valioso, de procriação e continuidade da espécie, tudo isso faz parte da justificativa proferida oralmente pelo deputado para um público presente, composto de funcionários, jornalistas e parlamentares. Nesta comissão os parlamentares eram majoritariamente mulheres, visto que a distribuição de parlamentares por comissões é feita pelos partidos políticos que recebem um número específico de cadeiras em cada comissão, número proporcional à sua cota de parlamentares em cada uma das casas legislativas - ainda que em nenhuma das comissões sobre mulher que aconteciam paralelamente víssemos uma exclusividade de mulheres nas comissões. Esse teor de proteção aparece em outras falas, inclusive na mesma reunião da Comissão Especial pelo Deputado Cleonâncio Fonseca (PP-SE), que abre e preside a reunião para eleger a presidência e vice-presidência da Comissão. ${ }^{5}$ Ele ressalta sua satisfação em presidir a sessão de criação da Comissão Especial do Estatuto da Mulher. Isto porque ele se sente muito "ligado à mulher".

Tenho uma história de vida toda ligada à mulher. Casei com uma filha única e, 3 meses depois, meu sogro morreu. Fui buscar minha sogra, que me impôs uma condição: viria com 2 irmãs que moravam com ela. Eu as trouxe. Assim, casei-me com 4 mulheres. Depois, tive a primeira, a segunda, a terceira e a quarta filhas. Tive seguidas 10 netas, e recentemente nasceu uma bisneta. Sinto-me um homem feliz por defender todas as causas das mulheres e prestigiá-las, pois vivo rodeado por elas, graças a Deus (BRASIL, 2004).

Novamente vemos uma argumentação simpatizante ao projeto de lei por aproximações dos deputados homens com mulheres por relações familiares. Nestas falas são feitas referências à esposa, sogra, irmãs, filhas, netas e bisneta. Esta condição de estar ligado à mulher traz o deputado ao protagonismo, como se a importância da mulher se desse a partir da sua vida, de homem e através de uma leitura pensada pela família. Este mesmo protagonismo é observado no teor da fala do deputado Fernando Gabeira (PT-RJ), que nesta mesma reunião, antes de iniciar a votação para a presidência, profere: "Sr. Presidente, como estou em outra Comissão, gostaria de saber se esta Comissão permite que os homens votem primeiro (risos)" (BRASIL, 2004). A fala de teor irônico é seguida de risos dos parlamentares. Na segunda reunião da Comissão Especial o deputado Renato Cozzolino, autor do PL, reforça seu apoio à proposta parlamentar,

\footnotetext{
${ }^{5}$ Segundo Regimento Interno da Câmara dos Deputados, "Presidirá a reunião o último Presidente da Comissão, se reeleito Deputado ou se continuar no exercício de mandato, e, na sua falta, o Deputado mais idoso, dentre os de maior número de legislaturas".
} 
É preciso, sim, juntar tudo isso; é preciso, sim, olhar a mulher como um ser especial - e não estou aqui para engrandecer ou diminuir. Mas a verdade é que todo homem tem, pelo menos, um grande amor na vida. E eu não sou diferente dos demais homens da face da terra. Parabéns, nobre Presidenta! Parabéns, nobre Relatora! Tenho certeza de que o Estatuto da Mulher será, no transcorrer deste ano, matéria muito discutida, e serão as senhoras - mães e avós - que darão a muitas outras senhoras mães e avós Brasil afora direitos não garantidos na Constituição, tais como exame preventivo e acompanhamento constante no pré-natal. Vivemos o dia-a-dia das comunidades mais carentes e sabemos que esse Estatuto não foi elaborado pensando na mãe do Renato, na esposa do Renato, na Presidenta da Comissão, na Relatora, ou em qualquer outro componente da Casa, mas, sim, naquelas senhoras, naquelas mães, naquela mulher sofrida das regiões mais pobres do nosso Brasil (BRASIL, 2004).

De novo vemos a mulher ser ilustrada por seu lugar na vida desses deputados; lugar que se dá através da família. Uma sugestão seria que talvez essas mulheres não sejam mulheres, mas são, antes, mães, esposas, filhas - todas essas figuras que dentro do ambiente familiar reforçam essa proteção advinda dos homens. Isto é extremamente importante, pois esse movimento demonstra uma exclusão de outro nível. A partir dessas falas poderíamos entender que o Estatuto da Mulher (2003) seria direcionado apenas para algumas mulheres, mas agora apenas mulheres vistas através dos homens. $\mathrm{O}$ que esses dados referentes ao Estatuto da Mulher nos mostram é que a percepção do que é mulher na produção das leis ainda parte de um cenário relacionado a um papel na sociedade que a vincula à família, maternidade, religião. Se examinássemos as leis ou aquilo que é apresentado como 'documento escrito' - projetos de lei, leis, pareceres, votos, justificação -, perceberíamos muito menos esse imaginário. Ou seja, se olhássemos apenas para o conjunto de leis e das propostas de leis formalizado nos 'documentos escritos' seríamos tentados a deduzir que a igualdade entre os sexos já está dada. Mas as falas que colocam a mulher vista através de homens e vista através da família que aparecem em falas em Comissão Especial nos mostram que o que poderíamos chamar de contexto de construção da categoria mulher, ou do que se entende por mulher quando se vê tal conceito nas leis, vem por meio desses (e talvez por mais) condicionantes. Consequentemente, se o conceito de mulher apresentado nos 'documentos escritos' em 2003 - projeto de lei, justificativa e emendas - mostra uma noção de mulher, aqui, no entanto, vemos que a noção de mulher é vista e embasada nessas relações entre homem e família. Onde mulher não seria, e nem almejaria ser igual a homem.

\section{Considerações finais}

Bruna FRANCHETTO, Maria Laura V. C. CAVALCANTI e Maria Luiza HEILBORN, em artigo publicado em 1980, descrevem o feminismo e as conquistas obtidas em direitos para mulheres como desdobramentos do individualismo moderno. Para as autoras, um dos anúncios do individualismo seria a Declaração dos Direitos do Homem, sendo esta uma forma de afirmar a dominância da ideologia individualista. Então o feminismo como "[...] movimento reivindica um entendimento da cidadania feminina igual à masculina: é a famosa luta pelos direitos iguais" (FRANQUETTO; CAVALCANTI; HEILBORN, 1981, p. 39-40). As autoras entendem todo esse processo de conquista de direitos das mulheres, que de fato foram alcançados via movimento feminista e de mulheres, como uma forma de transformá-las e colocá-las na categoria indivíduo, onde estas estariam buscando sua individualização e a igualdade implícita neste modelo. Entretanto, as próprias autoras indicam um dos problemas que o feminismo encontra ao "apoiar-se nessa lógica reivindicativa e igualitária" (FRANQUETTO; CAVALCANTI; HEILBORN, 1981, p. 40), pois esse sistema tornaria visível a hierarquia presente no sistema igualitário. Como Silva (2008) apontou, a igualdade e a própria inclusão da mulher na categoria cidadão não garantem a sua efetiva inclusão e cidadania, visto que ambas as categorias são masculinas, feita para e por homens. Se essas leituras apontam dificuldades em se obter uma igualdade entre homens e mulheres, tentamos demonstrar como isso está denunciado no processo de produção de leis através das discussões em torno da categoria jurídica mulher com a tramitação do Estatuto da Mulher entre 2003 e 2004.

Enquanto parte dos 'documentos escritos' afirmava a isonomia da Constituição Federal e tentava regular o Estatuto da Mulher a partir desse critério, parte dos discursos que passaram a ser proferidos em Comissão Especial para discussão do projeto de lei do Estatuto da Mulher reafirma a condição de mulher como materna, feminina e familiar. O contraste nestas duas formas de fazer referência à mulher (ainda que em alguns momentos, principalmente nos debates, a categoria jurídica e mulheres parlamentares sejam tratadas da mesma maneira) retoma debates que necessitariam emancipar mulher da família para conquistar, de fato, igualdade jurídica. Essa associação de mulher à família e sua definição como própria de espaços de dentro da casa foram descritas por um modelo de família brasileira (Gilberto FREYRE, 1933; 1964). Ângela Mendes ALMEIDA (1987) analisa a família brasileira ao mesclar a noção de família patriarcal de Gillberto Freyre com a noção de família burguesa que teria chegado ao Brasil com a vinda da família real em 1808, o que mudaria não apenas a noção de família, mas como mulher era vista através da 
mesma e onde ela ficaria, se fora ou dentro da casa. Para Maria Ângela D'Incao (2004), com a chegada da família burguesa nasce também uma nova mulher, "marcada pela valorização da intimidade e da maternidade" (p. 223). Almeida (1987) entende que esse modelo de família nuclear burguesa mantinha uma "mística da natureza feminina" (p. 57). Isto promovia uma desigualdade entre homens e mulheres sustentada por uma diferença biológica recaindo sobre as últimas causas naturais como o "instinto materno". Almeida (1987) aponta que se a noção de família burguesa advinha de uma mentalidade igualitária do liberalismo burguês, este modelo explicava que a igualdade seria natural entre homens, enquanto a relação entre homens e mulheres seria posta como naturalmente desigual, mantendo assim o lugar de mulheres como natural e justificado por aspectos biológicos. D' Incao (2004) reforça que no início do século XIX a vida urbana era praticamente inexistente no Brasil, e que com o desenvolvimento das cidades e da vida burguesa no século XIX a vida doméstica passa a ser interiorizada na casa, que com os anos vai mudando sua arquitetura de forma a abrigar cada vez mais a intimidade familiar preservada do espaço de fora. "Cada vez mais é reforçada a ideia de que ser mulher é ser quase integralmente mãe dedicada e atenciosa, um ideal que só pode ser plenamente atingido dentro da esfera da família 'burguesa e higienizada'” (D'INCAO, 2004, p. 229).

Formas de ver a mulher através da maternidade, de um papel social na família, foram apontadas em outros contextos por outras autoras (Fabiola ROHDEN, 2003; VIEIRA, 201 1). Segundo Lia Zanotta MACHADO (1998), o conservadorismo em relação à mulher enquanto mãe ainda barrava, de certa maneira, a discussão sobre aborto na Câmara dos Deputados, ainda que a partir de 2005 comecem a ser discutidos projetos visando à descriminalização do aborto pela Comissão de Seguridade Social e Família da Câmara Federal de Deputados. Rohden (2003) mostra como percepções da mulher no século XIX e primeira metade do século XX, pela medicina em intersecção com disputas jurídicas e o próprio Estado, recorriam a esta ideia de "mulher família - reprodução". Tais características - "o desejo de ser mãe", a maternidade, o amor materno - eram tidas como intrínsecas à mulher e respaldadas na própria medicina. No contexto estudado pela autora, que analisava em sua maior parte teses de medicina do século XIX e início do século $X X$, vemos a mulher ser descrita inclusive como ser inferior ao homem. Ser esse que garantiria o desenvolvimento da nação através dos filhos gerados. Ela demonstra como as relações de casamento, afetivas, sexuais, foram previstas e controladas pela medicina e incorporadas em discursos jurídicos e estatais. Isto, até a década de 40 , quando a autora fecha o seu recorte empírico. Ou seja, ainda que se pensasse que garantia de direitos às mulheres na década de 30 e 40 fosse fruto de uma maior individualização da mulher, estes ganhos se dão pensados numa esfera de coletivização da mulher: protegê-la para proteger os filhos, a família.

Assim, enquanto avanços em direitos para mulheres promoviam a perda da tradição que seria a base da família, processo que, segundo Cynthia SARTI (1995), foi impulsionado pelas mulheres com o controle da reprodução, o que permitiu reformular seu lugar nos espaços em que ocupavam dentro e fora da casa, acabava ainda residindo uma vontade de viver junto. O problema, então, se daria por querer tanto esta individualidade quanto manter a família (SARTI, 1995). O percurso de transformação da categoria jurídica mulher demonstra que ainda que direitos fossem atribuídos a mulheres, muito se restringia em prol da família. Mantinha-se assim o homem como chefe de família, onde o direito de trabalho atribuído à mulher recairia como um poder de decisão do homem, esposo ou pai. Na Constituição brasileira ałual, enquanto o termo família sofre uma ampliação, o termo mulher tenta se emancipar do primeiro e chegar ao status de cidadã (GENOFRE, 1995; VERUCCI, 1994). Entretanto, mesmo nas leis é preciso notar que contradições em relação a essa emancipação e à igualdade jurídica da mulher continuaram coexistindo. Paradoxalmente à emancipação da família em termos jurídicos, mulher apareceu em debates legislativos realocada em papéis e condições familiares. A recorrência de falas de parlamentares associando mulheres a papéis familiares nos direciona a uma revisão do processo de tal - e suposta - emancipação.

Este artigo também demonstrou ser necessário deslocar o olhar do 'documento escrito' para notar como mulheres são colocadas nas falas observadas nos 'registros' sobre a mesma proposição legislativa. Contrastar estes dois tipos de documentos aponta que suas diferentes formas produzem diferentes noções de mulher. A partir da análise do teor das falas na Comissão Especial, e comparando-os com os 'documentos escritos' em 1937, pudemos perceber como mulheres são postas de forma distinta de homens, e ao conectar os discursos associando mulher a papéis femininos e familiares a uma ideologia retrógrada notamos como este movimento contraria o processo evolutivo da mesma nas leis do país. Só assim percebemos que os 'discursos' proferidos na Comissão do Estatuto da Mulher em 2004 continuavam mantendo mulher em uma noção que indica um momento em que mulheres não eram e não almejavam possuir a mesma igualdade jurídica que homem.

Ao analisar o processo de tramitação do PL do Estatuto da Mulher em 2003 percebemos que diversas categorias de mulher são mobilizadas nesse percurso. Enquanto a legislação brasileira parte de uma categoria jurídica, "mulher", que presumiria a igualdade jurídica destas como Pessoa 
Física na Constituição Federal, vemos que esta afirmação foi conquistada através de um processo de mobilização de mulheres - o que inclusive culminou em avanços na Constituição atual para outras categorias além de mulher. O projeto de lei do Estatuto da Mulher, ao ser apresentado, levanta um debate aparente nos 'documentos escritos' de quem seriam as mulheres alcançadas pelo Estatuto e qual seria esta função se a categoria jurídica mulher já partiria de uma pressuposta igualdade, o que implicaria igualdade entre homens e mulheres, mas também entre mulheres e mulheres. O Estatuto da Mulher de 1937 aparece mostrando uma contradição entre as categorias mulheres nos dois momentos, sendo que em 1937 mulher não era categoria igual a homem em todos os aspectos, possuindo valores específicos e diferentes daquele. Já nos 'discursos' proferidos em relação ao projeto de lei do Estatuto da Mulher de 2003 a categoria mulher acionada parece ser colocada de forma diferente daquela definida pelos 'documentos escritos' apresentados sobre o Estatuto da Mulher de 2003. É como se ali mulher fosse uma categoria mais próxima àquela de 1937, onde ela não era igual a homem. A forma como os discursos se colocam, em sua maioria partindo de homens e se referindo às mulheres, vai nos mostrando que o que está em questão não é apenas uma categoria jurídica, mulher. O que parece estar exposto ali é um ideal de mulher que perdura desde pelo menos 1937, e que retrocede todos os avanços conquistados nos últimos anos.

\section{Referências}

ALMEIDA, Ângela Mendes. "Notas sobre a família no Brasil". In: ALMEIDA, Ângela Mendes. Pensando a família no Brasil. Rio de Janeiro: Espaço e Tempo; EDUFRRJ, 1987. p. 53-66.

ALVES, Branca Moreira. Ideologia e feminismo: a luta da mulher pelo voto no Brasil. Petrópolis: Vozes, 1980.

BRASIL. Câmara dos Deputados. Projeto de Lei $n^{\circ} 1.399$ de 2003. Dispõe sobre o Estatuto da Mulher e dá outras providências. Brasília, DF, 2003. Disponível em: http://www.camara.gov.br/ proposicoesWeb/prop_mostrarintegra?codteor=145460. Acesso em 08/06/2016.

BRASIL. Câmara dos Deputados. Emenda n 1 de 2004 do Projeto de Lei n 1.399 de 2003. Brasília, DF, 2004. Disponível em: http://www.camara.gov.br/proposicoesWeb/fichadetramitacao?idProposicao $=157204$. Acesso em 08/06/2016.

BRASIL. Câmara dos Deputados. Emenda n 4 de 2004 do Projeto de Lei n 1.399 de 2003. Brasília, DF, 2004. Disponível em: http://www.camara.gov.br/proposicoesWeb/fichadetramitacao?idProposicao $=157255$. Acesso em 08/06/2016.

BRASIL. Câmara dos Deputados. Emenda n 8 de 2004 do Projeto de Lei $n^{\circ} 1.399$ de 2003. Brasília, DF, 2004. Disponível em: http://www.camara.gov.br/proposicoesWeb/fichadetramitacao?idProposicao $=157268$. Acesso em 08/06/2016.

BRASIL. Câmara dos Deputados. Emenda n 21 de 2004 do Projeto de Lei n 1.399 de 2003. Brasília, DF, 2004. Disponível em: http://www.camara.gov.br/proposicoesWeb/fichadetramitacao?id Proposicao = 157290. Acesso em 08/06/2016.

BRASIL. Projeto $n^{\circ}$ 736, de 1937. Crêa o Estatuto da Mulher. Brasília: Arquivo da Câmara dos Deputados, 1937. [Localização: Arquivo da Câmara dos Deputados]

BRASIL. Constituição (1988). Constituição da República Federativa do Brasil: promulgada em 5 de outubro de 1988. Organização do texto: Juarez de Oliveira. 4. ed. São Paulo: Saraiva, 1990. 168p. (Série Legislação Brasileira)

CÂMARA DOS DEPUTADOS. Mulher e cidadania - 80 anos do voto feminino no Brasil 1932-2012. Brasília, 2014.

CARVALHO, Lianda Lima. 'Um estudo sobre o 'Lobby do Batom' na construção da Constituição Federativa de 1988". In: $7^{\circ}$ ENCONTRO ANUAL DA ANDHEP - Direitos Humanos, Democracia e Diversidade, UFPR, Curitiba (PR), 2012.

COSTA, Ana Alice Alcântara. "O movimento feminista no Brasil: dinâmicas de uma intervenção política”. Revista Gênero, Niterói, v. 5, n. 2, p. 09-35, 2013.

D'INCAO, Maria Ângela. "Mulher e família burguesa". In: DEL PRIORE, Mary; BASSANEZI, Carla (org.). História das Mulheres no Brasil. São Paulo: Contexto, 2004.

FONSECA, Claudia; CARDARELLO, Andrea. "Direitos dos mais e menos humanos". Horizontes Antropológicos, Porto Alegre, ano 5, n. 10, p. 83-122, 1999. 
FRANCHETTO, Bruna; CAVALCANTI, Maria Laura V. C.; HEILBORN, Maria Luiza. "Antropologia e Feminismo". In: FRANCHETTO, Bruna; CAVALCANTI, Maria Laura V. C.; HEILBORN, Maria Luiza. Perspectivas Antropológicas da Mulher 1. Rio de Janeiro: Zahar, 1981 [1980]. p. 11-47.

FREYRE, Gilberto. Casa-grande \& senzala: formação da família brasileira sob o regime da economia patriarcal. Rio de Janeiro: José Olympio, 1933.

FREYRE, Gilberto. "The Patriarchal Basis of Brazilian Society". In: MAIER, Joseph; WEATHERHEAD, Richard Whitney (org.). Politics of Change in Latin America. New York: Praeger, 1964 [1933]. p. 153-1 73.

GENOFRE, Roberto Maurício. "Família: uma leitura jurídica". In: FALCÃO, Maria do Carmo. A família contemporânea em debate. São Paulo: Cortez, 1995.

HULL, Matthew S. "Documents and Bureaucracy". Annual Review of Anthropology, n. 41, p. 251-267, 2012.

INDALENCIO, Maristela Nascimento. Estatuto do Idoso e Direitos Fundamentais: fundamentos da proteção da pessoa idosa no ordenamento jurídico brasileiro. 2007. Dissertação (Mestrado) Universidade do Vale do Itajaí, Itajaí, Brasil.

MACHADO, Lia Zanotta. "Gênero: Um Novo Paradigma". Cadernos PAGU, São Paulo, p. 107-125, 1998.

MARQUES, Teresa Cristina de Novaes. Perfil Parlamentar: Bertha Lutz. Brasília: Câmara dos Deputados, 2016.

ORIÁ, Ricardo. "Mulher e Cidadania: a conquista do voto feminino no Brasil". Caderno Aslegis, n. 38, p. 30-38, 2009.

PITANGUY, Jacqueline. As mulheres e a Constituição de 1988, 1988. Disponível em: www.cepia.org.br/ images/nov089.pdf. Acesso em 30/05/2015.

RILES, Annelise. "Introdution: In Response". In: RILES, Annelise (org.). Documents. Artifacts of Modern Knowledge. Michigan: University of Michigan, 2006.

ROHDEN, Fabiola. A arte de enganar a natureza: contracepção, aborto e infanticídio no início do século XX. Rio de Janeiro: FIOCRUZ, 2003.

SARTI, Cynthia. "Feminismo no Brasil: uma trajetória particular". Cadernos de Pesquisa, São Paulo, n. 34, p. 38-47, 1988.

SARTI, Cynthia. "Família e individualidade: um problema moderno". In: FALCÃO, Maria do Carmo (org.). A família contemporânea em debate. São Paulo: Cortez, 1995.

SILVA, Salete Maria da. "O Legado Jus-Político do Lobby do Batom Vinte Anos Depois". In: XXI ENCONTRO REGIONAL DE ESTUDANTES DE DIREITO E ENCONTRO REGIONAL DE ASSESSORIA JURÍDICA UNIVERSITÁRIA, 2008, Crato-CE.

SOUSA, Lia Gomes Pinto de; SOMBRIO, Mariana Moraes de Oliveira; LOPES, Maria Margaret. "Para Ler Bertha Lutz". Cadernos Pagu, n. 24, p. 315-325, 2005.

SOW, Marilene Mendes. "A participação feminina na construção de um parlamento democrático". E-Legis-Revista Eletrônica do Programa de Pós-Graduação da Câmara dos Deputados, n. 5, p. 79-94, 2010.

VERUCCI, Florisa. O direito da mulher em mutação: os desafios da igualdade. Belo Horizonte: Del Rey, 1999. 264p.

VERUCCI, Florisa. "Mulher e Família na Nova Constituição Brasileira". In: TABAK, Fanny; VERUCCI, Florisa (org.). A difícil igualdade: os direitos da mulher como direito humanos. Rio de Janeiro: Relume-Damará, 1994. p. 55-75.

VIEIRA, Miriam Steffen. Categorias Jurídicas e violência sexual: uma negociação com múltiplos atores. Porto Alegre: EDUFRGS, 2011.

Bruna Potechi (brunapotechi@gmail.com) é doutora em Antropologia Social pela Universidade Federal de São Carlos, graduada em Ciências Sociais pela UFSCar (2009) e mestra em Antropologia Social no Programa de Pós-Graduação em Antropologia Social (PPGAS) na mesma universidade 
(2013). No Doutorado defendeu tese sobre a produção de leis no Congresso Nacional através de uma etnografia com documentos entre os anos de 2003 e 2004 na Câmara dos Deputados em Brasília. Atua nos temas de gênero, burocracia, estado e direito. Foi bolsista FAPESP de Doutorado (2013-2018).

\section{COMO CITAR ESSE ARTIGO DE ACORDO COM AS NORMAS DA REVISTA}

POTECHI, Bruna. "As mulheres dos estatutos no Congresso Nacional Brasileiro". Revista Estudos Feministas, Florianópolis, v. 27, n. 1, e50110, 2019.

\section{CONTRIBUIÇÃO DE AUTORIA}

Não se aplica

\section{FINANCIAMENTO}

Financiamento FAPESP para Projeto de Doutorado Regular Processo 2013/14036-7

\section{CONSENTIMENTO DE USO DE IMAGEM}

Não se aplica

APROVAÇÃO DE COMITÊ DE ÉTICA EM PESQUISA

Não se aplica

\section{CONFLITO DE INTERESSES}

Não se aplica

\section{LICENÇA DE USO}

Este artigo está licenciado sob a Licença Creative Commons CC-BY. Com essa licença você pode compartilhar, adaptar, criar para qualquer fim, desde que atribua a autoria da obra.

\section{HISTÓRICO}

Recebido em 17/04/2017

Reapresentado em 19/06/2018

Aprovado em 05/07/2018

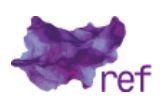

